\title{
Knowledge transfer in technological innovation clusters
}

\section{Technological innovation clusters}

\author{
Vania Lopes Simoes Fioravanti
}

Postgraduate Program in Business Administration, Paulista University (UNIP), Sao Paulo, Brazil

Fabricio Stocker

Brazilian School of Public and Business Administration, Getulio Vargas Foundation (FGV-Ebape), Fundação Getúlio Vargas, Sao Paulo, Brazil, and

Flavio Macau

School of Business and Law, Edith Cowan University, Perth, Australia

\begin{abstract}
Purpose - The aim of this research is to analyze the knowledge transfer process in technological innovation clusters. The problem of the study addresses how organizations can act in a network to enhance experiences and gains, particularly in the aspect of knowledge management.

Design/methodology/approach - The study is qualitative, applied through a case study, cross-sectional and multiple sources of evidence - semistructured interviews, nonparticipant observation and analysis of documents and secondary institutional data. The case analyzed was the Technology Park of São José dos Campos, in Brazil, involving private companies, governmental organizations, universities and research institutions.

Findings - The results reinforce the arguments that the transfer of knowledge is influenced by factors, facilitators or inhibitors such as: cooperation, relationship with institutions, workforce mobility and geographical proximity, influencing the competitiveness and performance of the organizations in the cluster. Research limitations/implications - This study advances the knowledge management literature in network environments, especially in technological innovation clusters, systematizing and highlighting the facilitating and inhibiting dimensions of knowledge transfer.

Practical implications - The present work has a direct dialogue with the managers and actors involved in the governance of these organizational arrangements with regard to increasing the capacity for creation and the dissemination of knowledge among organizations, educational institutions, government and companies.

Originality/value - There is a presence of aspects indicating that knowledge goes beyond borders through dynamic and collaborative structures, reinforcing the premise that clusters must be perceived as an evolutionary system, whose result of interactions leads to a superior joint capacity.
\end{abstract}

Keywords Cluster, Technology park, Knowledge management, Cooperation

Paper type Research paper

\section{Introduction}

Knowledge transfer is one of the fundamental elements for survival in the network society era. In this sense, cooperation networks can develop systems for exchanging information and knowledge, based on interaction with other organizations (Powell, 1998), standing out for their superior ability to distribute knowledge among their members (Williams \& Pouder, 2019).

(C) Vania Lopes Simoes Fioravanti, Fabricio Stocker and Flavio Macau. Published in Innovation \& Management Review. Published by Emerald Publishing Limited. This article is published under the Creative Commons Attribution (CC BY 4.0) licence. Anyone may reproduce, distribute, translate and create derivative works of this article (for both commercial and non-commercial purposes), subject to full attribution to the original publication and authors. The full terms of this licence maybe seen at http:// creativecommons.org/licences/by/4.0/legalcode. 
INMR

20,1

From a theoretical point of view, networks can be studied from different approaches, among which are cluster studies, as well as the geographical concentration of companies (Humphrey, Todeva, Armando, \& Giglio, 2019). The recognition that this concentration results in effects that lead to superior performance has been further studied by authors such as Todeva, Knoke \& Keskinva (2007), Bagley (2019) and Santos (2020).

In terms of knowledge transfer between organizations in a cluster, there are factors that can inhibit or facilitate this process, and understanding these factors can lead to better management, facilitating the flow of knowledge (Fioravanti \& Macau, 2017; Costa Neto, Perin, \& Ferreira, 2019; Silva, Feldmann, Spers, \& Bambini, 2019). In this context, the present work is located, whose objective is to analyze the transfer of knowledge through a case study, identifying the factors that influence this process.

The São José dos Campos Technology Park was chosen as the object of study, and it was created with the purpose of concentrating companies, teaching and research institutions, as well as organizations of other natures, aiming at the technological and economic development of the region through the sharing of space between entrepreneurs, entrepreneurs and science and research institutes (Minello, Marinho, \& Bürger, 2017; Roldan, Hansen, \& Garcia-Perezde-Lema, 2018). Given its nature, which involves several types of companies and organizations with relationships with each other, the object of study was analyzed from the perspective of interorganizational networks, complementing with specific aspects of the cluster due to the geographical concentration factor.

The problem of the study addresses how organizations can act in a network to enhance experiences and gains, particularly in the aspect of knowledge management. In acting in a technology cluster, such as a Technology Park, companies, entrepreneurs and teaching and research institutions seek to join efforts for technological development. Hence the research question: how does the cluster influence the knowledge transfer process between organizations?

The objective of analyzing the knowledge transfer process in interorganizational networks in the context of the cluster and the factors that influence this process presents the problem in defining a research methodology model that captures this process. Despite the recognition of the relevance of these aspects of the investigated phenomenon, this study is dedicated to identifying the factors that influence the knowledge transfer process in interorganizational networks in the context of a technology cluster without, however, looking for cause and effect relationships.

\section{Theoretical foundation}

In contemporary society, the discussion of knowledge concepts in organizations has focused on its strategic dimension, with authors discussing the transfer of knowledge between the units of a company (Williams \& Pouder, 2019), while other theorists have focused on the flow of knowledge between a multinational company and its subsidiaries as well as in the national innovation system (Lundvall, Johnson, Andersen, \& Dalum, 2002; López-Rubio, Roig-Tierno, \& Mas-Verdú, 2021) and also those who studied the importance of knowledge transfer for innovation and competitiveness (Aguiar, Pereira, Donaire, \& Nascimento, 2017; Bittencourt, Zen, \& Prévot, 2019).

Knowledge transfer in organizations is the process by which a unit (person, sector or company) is affected by the experience of another unit (Argote \& Ingram, 2000). Thus, it appears that, although knowledge is transferred more quickly between organizations operating in a network than isolated companies, its analysis involves greater complexity (Powell, 1998). For some authors, knowledge transfer can be measured by identifying the changes generated in the company's knowledge or in its performance because companies increase their performance by making use of the knowledge acquired with the network in which they operate (Argote \& Ingram, 2000; Williams \& Pouder, 2019; Santos, 2020). 
The dimensions of knowledge transfer have been explored in recent studies, as approached by Costa Neto et al. (2019), which listed: (1) the motivation for engagement in collaboration, (2) the transfer activities carried out in interactions, (3) the intervening factors of the transfer process, (4) the facilitators and barriers to the transfer of knowledge and (5) the results of innovation with the transfer process.

In this study, in order to verify the occurrence of knowledge transfer, the following indicators will be considered as observable factors of the knowledge transfer process, based on Correia (2007), which were adopted due to their verifiable and observable aspect, and together with the instrumental vision addressed in the dimensions proposed by Costa Neto et al. (2019). The authors pointed out that knowledge transfer can arise from different angles, among which the following stand out: (1) adoption of new technologies, (2) reorganization of work, (3) more skilled labor, (4) learning organizational, (5) management practices, (6) business policies, (7) entrepreneurial capacity of companies and the region, (8) work organization and (9) tacit and codified knowledge.

\subsection{Knowledge transfer in clusters}

Networks can be studied from different theoretical approaches (Stocker, Mascena, Azevedo, $\&$ Boaventura, 2019). Among the existing approaches are cluster studies, understood as the geographical concentration of companies. In the literature, clusters and networks are close concepts, with cluster being recognized as a particular type of network that, broadly, would be associated with a sectorial and geographic concentration of companies (Cassanego Júnior, Boaventura, Azevedo, \& Telles, 2019). For this study, the concept of cluster is defined by Zaccarelli, Telles, Siqueira, Boaventura, \& Donaire (2008), as a group of companies that are dedicated to producing the same type of product as an evolutionary system and whose result of the interactions is greater capacity than they would achieve by working alone. The choice for this concept is due to the flexibility of applying the model of Zaccarelli et al. (2008) in empirical research, since it involves the coexistence of different foundations that constitute observable evidence.

In the literature, the number of studies dealing with knowledge management in the context of networks and clusters is vast, investigating its importance for competitiveness (Porter, 1990; Aguiar et al., 2017), the impact on local economies (Zucker, Darby, \& Armstrong, 1998; Siqueira, Rocca, \& Telles, 2015; Silva et al., 2019); for the development of science and technology (Martins, Fiates, Dutra, \& Venâncio, 2015; Jiang, Goel, \& Zhang, 2019), for innovation (Cohen \& Levinthal, 1990; Minello et al., 2017). Williams \& Pouder, 2019; Bittencourt et al., 2019) and in the university-company relationship (Vásquez-Urriago, BargeGil, \& Rico, 2016; Castro, Nagano, \& Ribeiro, 2019). The spillover of knowledge is thus understood as the promotion and dissemination of knowledge about people, about the business and organizational fabric and about the local space.

It appears that concepts of network theories, when combined with the effects of spatial proximity, become an important conceptual combination to understand how sectors develop skills and knowledge more quickly than others, an effect that can be observed in a cluster. The more companies share conditions and experiences, the more their absorption capacity increases and the more easily they will be able to participate in the knowledge transfer process (Tallman, Jenkins, Henry, \& Pinch, 2004; Miranda \& Borges, 2019).

In this way, a knowledge network emerges in the cluster through a structure of links between the actors, which facilitates learning and the transfer of knowledge in this network (Tallman et al., 2004). In general terms, the different forms of knowledge networks include subcontracting, supply chains, formal and informal collaborations, relationships between employees and family members, participation in trade associations, partnerships and the movement of people between companies at different levels (Zeng, 2008; Pereira, Silva, Lavoie, 
INMR

20,1

\section{6}

\& Porto, 2018). Therefore, a knowledge network is a structure of interconnected actors that facilitate learning in companies and organizations.

In this research, knowledge transfer is considered the process of disseminating, sharing and transferring tacit and explicit knowledge through formal and informal practices and obtained through an existing knowledge network, thus understood as a structure of links between the actors that allow learning between companies and organizations (Tallman et al., 2004).

\subsection{Factors in the knowledge transfer process}

More than discussing the components and terminologies involved in the knowledge transfer process, it is important to consider the factors that influence this process. Szulanski (2000) described a series of factors considered to inhibit knowledge transfer; the author divided these factors into motivational factors and barriers to knowledge. In this category, three main factors were identified: (1) lack of absorption capacity, (2) causal ambiguity and (3) relationship between the emitter and the receiver of knowledge.

Paulin and Winroth (2013) discussed the transfer of knowledge as a process influenced by facilitating and inhibiting factors, basing their arguments on studies of strategies for implementing learning processes by companies. The authors classified aspects involved in knowledge transfer as facilitating factors, transfer inhibiting factors and obstacles, considering in their model the following categories: actor, activity, source, receiver, context and environment. The model proposed by the authors can be summarized in Table 1.

This terminology is based on the idea that the knowledge transfer process can be influenced in different ways, which can be through facilitating factors (which influence positively), inhibiting factors (which influence negatively) or obstacles (which obstruct the process).

There is a difference in the knowledge transfer process between the different levels existing in a cluster, such as in the relationship between suppliers and producers, leading companies and small companies (Sarach, 2015). An additional point to be commented on is

\begin{tabular}{lll}
\hline Type of influence & Factor & Component \\
\hline Facilitator & Frequency/intensity of activities & Activity \\
& Ability to share & Actor/source \\
& Absorption capacity & Actor/receiver \\
& Willingness/motivation/leadership & Actors \\
& Strength of group ties/size of organizations/social capital & Context \\
& Time availability & Context \\
& Information technology systems & Mean \\
& Learning culture & Actor/receiver \\
& Physical space/shared culture & Context \\
& Ambiguity & Actor/source \\
Inhibitor & Distance of knowledge & Actors \\
& Physical distance/organizational distance/uncertainty environment & Context \\
& Linguistic differences & Mean \\
& Protectionism & Actor/source \\
& Distance of age and gender & Actors \\
& Technology/skills & Actor/receiver \\
& Confidence & Actors \\
Obstáculo & Infrastructure & Mean \\
& Communication channels & Mean \\
Inibidor/Facilitador & Type of knowledge & Context \\
Source(s): Adapted from Paulin and Winroth (2013) &
\end{tabular}

Source(s): Adapted from Paulin and Winroth (2013)
Table 1.

Classification of factors that influence knowledge transfer 
that the existing relationships in the cluster, whether these relations of cooperation or not, intensify the exchange of knowledge between the participants. There are studies with evidence that, even when cooperation between members of the cluster is not recognized, knowledge transfer occurs (Hoffmann, Lopes, \& Medeiros, 2014). Thus, the knowledge transfer process in the cluster has a multidimensional aspect, which can be analyzed in different dimensions: cooperation, relationship with support institutions, workforce mobility and proximity, as indicated by authors such as Molina-Morales (2001), Asheim and Isaksen (2002), Morosini (2004), Malmberg \& Power (2005), Zeng (2008), Castro et al. (2019) and Jiang et al. (2019).

Cooperation, in the context of knowledge transfer, involves the exchange of techniques, information sharing and complementarity between members of the cluster (Asheim \& Isaksen, 2002; Zeng, 2008). Among the cooperative relationships that emerge in the cluster, authors highlighted the importance of informal social relationships, including family members, in the knowledge transfer process in regions where the cluster exists (MolinaMorales, 2001; Morosini, 2004), as well as the impact of motivation or propensity of companies to get involved in knowledge and technology transfer activities (Arvanitis, Kubli, \& Woerter, 2011; Williams \& Pouder, 2019) or partnerships in the triple helix context with companies/ industry, government and university (Pique, Berbegal-Mirabent, \& Etzkowitz, 2018).

Another aspect to be considered is that acting in a cluster can raise the fear of opportunistic behavior and the risk of loss of competitiveness, influencing the sharing of information and knowledge (Jarvenpaa \& Wernick, 2011; Aguiar et al., 2017). Thus, paradoxically, there is a coexistence of collaboration and competition in the cluster (Hoffmann et al., 2014), which in the aspect of knowledge transfer manifests itself in the fear of loss of competitiveness and risk of opportunism when sharing knowledge with others companies (Jarvenpaa \& Wernick, 2011; Aguiar et al., 2017), while intensifying the motivation for knowledge sharing when there is credibility between the parties (Williams \& Pouder, 2019).

As previously discussed, in a cluster there may be the performance of support institutions that provide support and assistance to participants (Ribeiro \& Nagano, 2018). These institutions may be of a public nature, such as universities and teaching and research institutions or private associations responsible for the governance of the cluster. The relations established with these support institutions are relevant to the transfer of knowledge, which can occur through technical knowledge, access to specialists, the supply of manpower with specific qualifications, the provision of courses and the holding of knowledge dissemination events (Asheim \& Isaksen, 2002; Hoffmann et al., 2014; Castro et al., 2019).

However, there are obstacles to the knowledge transfer process in this type of relationship, as companies often do not feel able to interpret and absorb the knowledge shared by the university Arvanitis et al. (2011), Ribeiro and Nagano (2018), presumably due to a lack of absorption capacity, corroborating the ideas of Cohen and Levinthal (1990).

Regarding the mobility of the workforce dimension, a cluster has the capacity to gather, in the same place, a significant number of people with specific skills. Thus, the movement of labor between the companies in the cluster, between the university and the companies, together with the geographical proximity, influence the transfer of knowledge (Asheim \& Isaksen, 2002; Malmberg \& Power, 2005).

Thus, a collective learning process occurs in the cluster through a network of informal contacts in face-to-face meetings and casual information flow (Williams \& Pouder, 2019), generating social behavior oriented toward the sharing of values and standards of conduct, involving professional and personal aspects (Zaccarelli et al., 2008). Among the cooperative relationships that emerge in the cluster, authors highlighted the importance of informal social relationships, including family members, in the knowledge transfer process in regions where the cluster exists (Molina-Morales, 2001; Morosini, 2004; Bagley, 2019). 
INMR

20,1

\section{8}

In light of the above, this paper presents and discusses five propositions with respect to the dimensions presented on the factors and process of knowledge transfer in clusters, as illustrated in Table 2. These proposals will guide the operationalization of the work and the analysis of the selected case, seeking to finally answer the research question about how the cluster (its dimensions of study) influences the knowledge transfer process of the companies that participate in it.

\section{Methodological procedures}

The case to be analyzed is the São José dos Campos Technology Park, involving companies, entrepreneurs and teaching and research institutions, in which nonparticipant observation was carried out through events that took place, as well as visits to conduct the interview. In the theme of networks, the network (all participants), the dyad and the actors involved in the network are suggested as the unit of analysis (Zaheer, Gozubuyuk \& Milanov, 2017).

The choice of the Technology Park arose due to the possibility of observing the phenomenon investigated, this being a place whose stated objective is to provide an environment for the generation and transfer of technological knowledge, while also presenting the characteristics that may come to classify it as a cluster, in addition to the researcher's access to the teaching and research institutions that make up the object.

\subsection{Source and data collection}

The following sources of evidence are used: primary (semistructured interviews and nonparticipant observation), secondary evidence sources (documents and institutional data available on the websites of companies and the Technology Park). The procedures that contributed to the validity of the research were adopted (Yin, 2010), including: to ensure the internal validity of the case study, the case study protocol, the pretest, the use of multiple sources were used evidence, the triangulation of data and the subsequent verification with the interviewees of the data collected and the interpretations made by the researcher.

The first stage of collecting evidence from this research consisted of semistructured interviews with the network's organizations, from November 1, 2016 to January 31, 2017, with

\begin{tabular}{|c|c|c|}
\hline Dimension & Propositions & Base authors \\
\hline $\begin{array}{l}\text { Participation in the } \\
\text { cluster }\end{array}$ & $\begin{array}{l}\text { Proposition } 1 \text { - participation in the } \\
\text { cluster intensifies the transfer of } \\
\text { knowledge between organizations } \\
\text { within the cluster }\end{array}$ & $\begin{array}{l}\text { Tallman et al. (2004), Todeva, Knoke } \\
\text { and Keskinva (2007), Hoffmann et al. } \\
\text { (2014), Vásquez-Urriago et al. (2016), } \\
\text { Bagley (2019) }\end{array}$ \\
\hline Cooperation & $\begin{array}{l}\text { Proposition } 2 \text { - cooperation intensifies } \\
\text { the transfer of knowledge between } \\
\text { organizations within the cluster }\end{array}$ & $\begin{array}{l}\text { Szulanski (2000), Arvanitis et al. } \\
\text { (2011), Hoffmann et al. (2014), Sarach } \\
\text { (2015) }\end{array}$ \\
\hline $\begin{array}{l}\text { Relationship with } \\
\text { institutions (support, } \\
\text { teaching, research) }\end{array}$ & $\begin{array}{l}\text { Proposition } 3 \text { - the relationship with } \\
\text { educational, research and support } \\
\text { institutions intensifies the transfer of } \\
\text { knowledge between organizations } \\
\text { within the cluster }\end{array}$ & $\begin{array}{l}\text { Etzkowitz (2003), Zaccarelli et al. } \\
\text { (2008), Arvanitis et al. (2011), } \\
\text { Hoffmann et al. (2014), Williams and } \\
\text { Pouder (2019) }\end{array}$ \\
\hline Workforce mobility & $\begin{array}{l}\text { Proposition } 4 \text { - the mobility of the } \\
\text { workforce intensifies the transfer of } \\
\text { knowledge between organizations } \\
\text { within the cluster }\end{array}$ & $\begin{array}{l}\text { Asheim and Isaksen (2002), } \\
\text { Malmberg and Power (2005), } \\
\text { Arvanitis et al. (2011), Hoffmann et al. } \\
\text { (2014) }\end{array}$ \\
\hline Proximity & $\begin{array}{l}\text { Proposition } 5 \text { - proximity intensifies the } \\
\text { transfer of knowledge between } \\
\text { organizations within the cluster }\end{array}$ & $\begin{array}{l}\text { Zaccarelli et al. (2008), Vásquez- } \\
\text { Urriago et al. (2016), Bagley (2019), } \\
\text { Williams and Pouder (2019) }\end{array}$ \\
\hline
\end{tabular}

Table 2.

Proposals for knowledge transfer in clusters 
respondents considered to be qualified by the organization and who held management positions, allowing, thus, an overview of the organizations' processes. Regarding the number of interviews, 09 in-depth interviews were conducted, including: 01 manager of an educational institution, 02 university researchers, 03 managers of companies in the cluster, 01 representative of governmental organization, 01 representing the support association, responsible for the management of the technology park. The concept of theoretical saturation was adopted (Eisenhardt, 1989) to define the number of interviews, thus understood as the point from which the incremental learning obtained with the new interviews was minimal, that is, when the new interviews added less information than previous interviews.

The second stage of evidence collection was observation, in which the phenomenon of knowledge transfer in clusters was investigated, in this case, the São José dos Campos Technology Park, seeking to capture the evidence in the field through an observation script, as proposed by Yin (2010). The observation was carried out from October 17, 2016 to January 31, 2017, as shown in Table 3. Interactions were observed in courses, lectures and events held in the unit of analysis in order to verify elements contained that facilitate or elements that inhibit the transfer of knowledge in the context in which the phenomenon occurs, as well as physical artifacts from the environments.

Finally, data were collected on secondary data produced or not by companies, such as news, bylaws, minutes of meetings, data on the institutional website of the collection unit and the organizations and documents provided by the interviewees, in order to identify patterns and to establish eventual relations between the organizations and based on the categories identified in the Interviews and Observation.

For data analysis, these steps were followed: (1) transcription of the interviews and collected data; (2) definition of nonequivalent dependent variables - pattern combination; (3) content analysis by means of analysis units for identification; and (4) data analysis by pattern combination (Barratt, Choi, \& Li, 2011). For the analysis of observational data, a system adapted from the theoretical coding proposed by Corbin \& Strauss (1996) was used.

\section{Analysis of results}

\subsection{Presentation of the case}

The Technology Park of São José dos Campos aims to promote technological research, development and innovation, for the benefit of the community and following the needs of the
Technological innovation clusters

\begin{tabular}{|c|c|c|}
\hline Order & Place and date & Description \\
\hline 01 & $\begin{array}{l}\text { Unifesp - campus São José dos } \\
\text { campos } \\
\text { Technology park of São José dos } \\
\text { campos } \\
\text { Date: 10/17/2016 - 1:00 p.m. to 5:00 } \\
\text { p.m. }\end{array}$ & $\begin{array}{l}\text { Lecture on intellectual property promoted by clark and Moet } \\
\text { and Unifesp, for the organizations of the technology park of } \\
\text { São José dos campos }\end{array}$ \\
\hline 02 & $\begin{array}{l}\text { Convention center-technology park of } \\
\text { São José dos campos } \\
\text { 10/19-20/2016 - 10:00 a.m. to 4:00 p.m. }\end{array}$ & $\begin{array}{l}\text { 3rd RM Vale TI - technology and innovation fair and } \\
\text { congress }\end{array}$ \\
\hline 03 & $\begin{array}{l}\text { Nucleus - São José dos campos } \\
\text { technology park association } \\
\text { 10/27/2016 - 9:00 a.m. to 2:00 p.m. }\end{array}$ & $\begin{array}{l}\text { Course "Paths to importation" carried out by Sebrae to } \\
\text { companies installed in the technology park of SJC }\end{array}$ \\
\hline 04 & $\begin{array}{l}\text { Business center II - technology park } \\
\text { of SJC } \\
\text { Date: } 11 / 16 / 2016 \text { - 3:00 p.m. to 6:00 } \\
\text { p.m. }\end{array}$ & $\begin{array}{l}\text { Inauguration of CAD I - development and innovation } \\
\text { support center }\end{array}$ \\
\hline
\end{tabular}

Table 3.

Collection of observational data 
INMR

20,1 region of São José dos Campos (São Paulo-Brazil). The adopted model is constituted as follows:

(1) Technology development centers (TDCs): partnerships between anchor companies, universities and research entities, focused on the development of specific technologies. Anchor companies are leaders in their segments, with their own Research and Development $-R \& D$ programs. In addition to providing visibility and credibility to the Park, they function as centers of attraction for medium and small companies;

(2) Universities and educational institutions: sources of knowledge and qualified labor present in the Park. The scientific and technical capacity of its researchers and the possibility of accessing laboratories constitute assets of great value.;

(3) Business centers (CEs): spaces designed to house technology-intensive small and medium-sized enterprises (SMEs), enjoying a synergistic environment and stimulating entrepreneurship, characterized by high connectivity and competitiveness.

The network has 72 actors, including companies, educational and research institutions (public and private), governmental organizations, organizations of other natures and the management association. Following this perspective, a network map was generated (Graph Figure 1), using the UCINET software. For the elaboration of the graph, all the actors in the network were listed and the existing links between them were identified. Ties were considered to be the relationships existing between organizations, such as partnership projects, research activities, joint technology development, joint activities, commercial relations and resource sharing (laboratories, physical spaces).

\subsection{Analysis of proposition 1 -participation in the cluster intensifies the transfer of knowledge between organizations}

Seeking the intersection of aspects of business networks and clusters with aspects of knowledge transfer, the first proposition of this study was formulated, as follows: Proposition 1: Participation in the cluster intensifies the transfer of knowledge between organizations within the cluster.

Some of the evidences that support the argument, present in the respondent' discourse, were:

[...]we get to know a lot of things, because the opportunities, the notices are many, you can't follow everything that is happening on the internet, know everything. So they help, and if you know this person, personally, it is different (Respondent 1).

[...]even if he doesn't talk to anyone and just circulates, I think it's already a differentiator, it's a huge advantage to be there. You don't have to leave here to go, they are already there. There is mainly an exchange of knowledge for the student, so to speak, on the spot. It is in the field, I have not just heard it, there is a proper theory. I went there and looked; I see it working (Respondent 3).

This selection refers to Nonaka, Takeuchi, \& Umemoto (1996) and Jiang et al. (2019), who claim that the creation and transfer of knowledge result from the interaction between tacit knowledge and explicit knowledge through social processes between the actors, not confined to the individual, and both dimensions interact in this process.

The existence of common objectives was verified, such as technological development projects and resource sharing that result in greater possibilities than they would reach if they acted in isolation, indicating that participation in the cluster intensifies the transfer of knowledge between the organizations inserted in the cluster, to the extent that organizations have access to the knowledge generated jointly. 


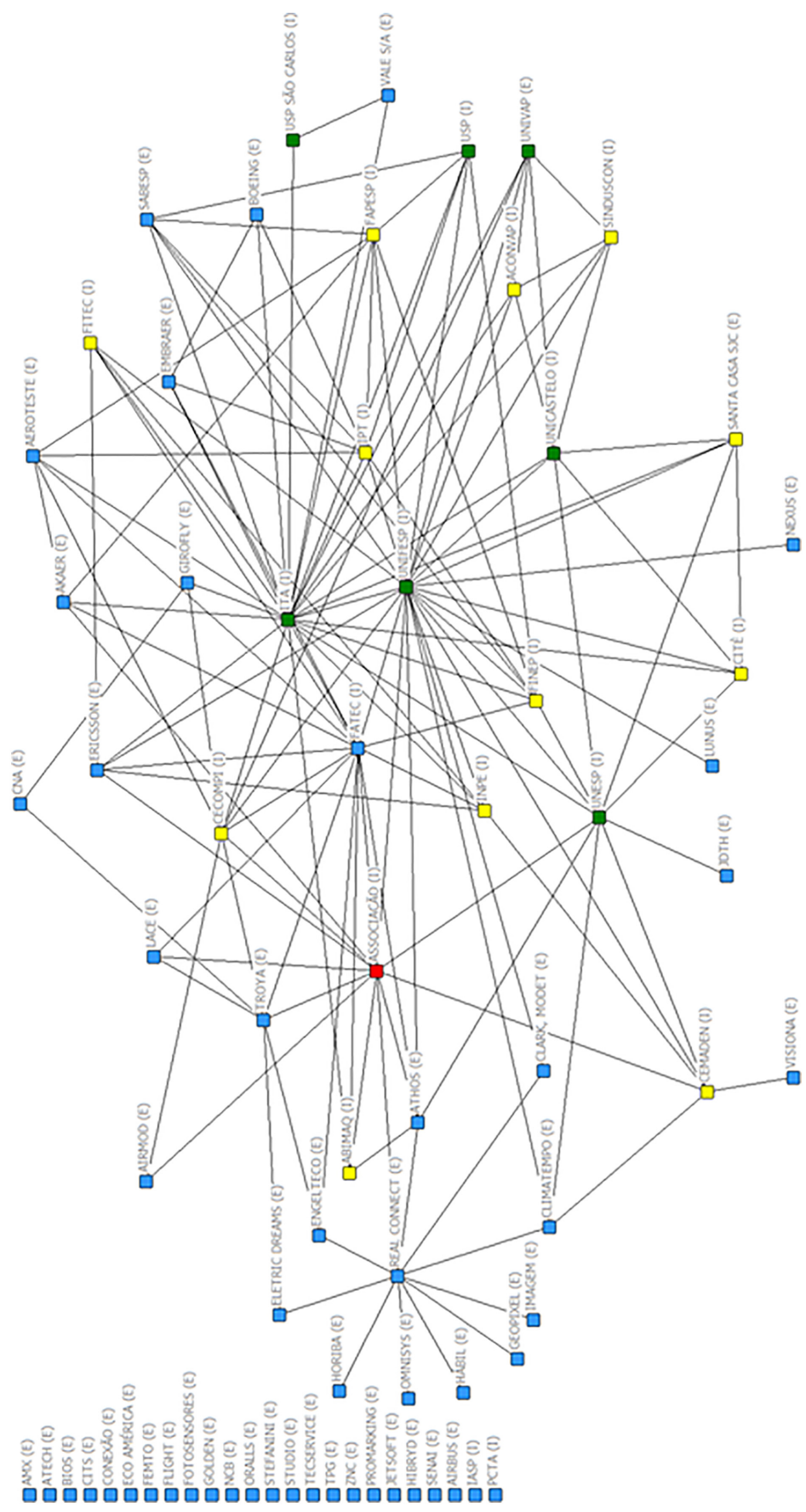

Technological innovation clusters 
INMR

20,1

There are several companies that I met, one of them works with virtual reality, it is a startup that is here, incubated. And we are starting to work together, I had an idea to do a service (...), using virtual reality, and we are doing the project together (Respondent 8).

There are critical systems labs that have a supercomputer here, which we use a lot. (...) We could be somewhere else, or even in the center of São José, which the square meter ends up being cheaper. But, again, for the beginning of the company, certainly being here ends up being more interesting. (Respondent 9).

During the observation, it was noticed that many events (actions and interactions between people in the formal and informal events held in the Park) were repeated. Exchanges of information on corporate policies (generation and exploitation of technological products) were witnessed, as well as exchange of tacit and coded knowledge, such as patent exploitation data, legal information about intellectual property, business models and development of new technologies (smart city, energy trends).

Organizations gain more knowledge when they participate in the cluster than when they operate in isolation. It was evident in the interviewees' statements that participation in the Technology Park allows access to an environment conducive to the exchange of knowledge, innovation and technological development, resulting from the relationship between organizations. In this sense, the cluster not only provides support for economic development, but acts as a facilitator in the process of creating and transferring knowledge between the organizations that compose it.

Thus, it is reinforced that a knowledge network is constituted in the cluster through a structure of links between the actors, which facilitates learning and knowledge transfer, and participation in this network allows organizations to absorb technological expertise from companies, partners and research and development entities. Thus, proposition 01 that participation in the cluster intensifies the transfer of knowledge between organizations within the cluster can be considered assertive.

\subsection{Analysis of proposition 2 - cooperation intensifies the transfer of knowledge between organizations within the cluster}

Continuing the analysis, the second proposition of this study is resumed, as follows: Proposition 2: Cooperation intensifies the transfer of knowledge between the organizations inserted in the cluster.

Evidence was found that the dimension of cooperation influences the knowledge transfer process in the São José dos Campos Technology Park, the evidence supporting the argument is:

Being in the same environment, it makes a difference. So, there is no formality, informality helps, they are people you know, you end up seeing them every day, so you have confidence and support. This is the great differential (Respondent 1).

If I see that a company is doing something interesting, if I see that a customer is in need of something that that solution, together with mine, will be interesting, it gives a good idea. I end up talking to this company "let's make a solution like this?(Respondent 9).

The motivation factor between the parties was observed in a strong way in the relations established with the support institution responsible for the management of the Park. This actor is responsible for receiving and publicizing visits from external organizations, such as representatives of the European Aerospace Cluster Partnership (EACP) for the exchange of experiences and visits by international delegations, acting as a gatekeeper for knowledge and innovation external to the cluster.

Secondary (documentary) data reinforce the premise that cooperation influences the transfer of knowledge between organizations within the cluster, through established 
relationships. These relationships mainly refer to partnerships for technological development projects between the Park's organizations and training of interest to the cluster carried out through partnerships of a voluntary nature.

Empirical evidence reinforces the statements of Asheim and Isaksen (2002), Zeng (2008), Arvanitis et al. (2011), Hoffmann et al. (2014), Sarach (2015), Roldan et al. (2018) and Costa Neto et al. (2019), in the sense that cooperation, in the context of knowledge transfer, involves the exchange of techniques, information sharing and complementarity between the members of the cluster.

Technological innovation clusters

\subsection{Analysis of proposition 3 - the relationship with educational, research and support institutions intensifies the transfer of knowledge between organizations within the cluster}

We return to the third proposition of this study, translated into the following sentence: Proposition 3: The relationship with educational, research and support institutions intensifies the transfer of knowledge between the organizations inserted in the cluster.

The evidence supporting the argument is:

And the Park holds a research and development meeting every six months, companies go there and present projects and universities present their areas of activity and then have tables where they then meet to discuss (Respondent 1).

However, the Technology Park does not have the expertise, it has some expertise, but not everything it needs (...). So, we have universities as partners. So, there is the CFD professor, the CAD professor, the market professor, the management professor. And according to the need, we seek this expertise to work with companies (Respondent 4).

Empirical evidence reinforces the influence of the relationship with educational institutions, verified in the structural analysis of the network. In the São José dos Campos Technology Park network, such institutions play a prominent role in the transfer of knowledge, connecting different groups and acting in different knowledge dissemination flows existing in the cluster. It is also possible to verify that, without the actors of teaching and research institutions, the network would be structured in isolated groups.

It is observed that Technology Parks and clusters have the capacity to enhance the use of knowledge between companies and universities (Zaccarelli et al., 2008), sharing resources that would be more costly to obtain otherwise (Etzkowitz, 2003; Williams \& Pouder, 2019). There is recognition on the part of companies that these institutions have relevance in the transfer of knowledge, which occurs through technical knowledge, access to specialists, supply of manpower with specific qualification, offering courses and holding events for the dissemination of knowledge and resource sharing.

There may be obstacles to the knowledge transfer process in this type of relationship, as companies often do not feel capable of interpreting and absorbing the knowledge shared by the university (Arvanitis et al., 2011), presumably due to a lack of knowledge absorption capacity (Cohen \& Levinthal, 1990).

Observational data reinforce the proposition that the relationship with educational, research and support institutions intensifies the transfer of knowledge between organizations within the cluster. Tacit knowledge sharing and dissemination events were observed, such as those related to patent exploitation and technological trends.

\subsection{Analysis of proposition 4 -workforce mobility intensifies knowledge transfer between organizations within the cluster}

Authors such as Asheim \& Isaksen (2002), Malmberg and Power (2005), Arvanitis et al. (2011) and Hoffmann et al. (2014) argue that the cluster still has the capacity to bring together a significant number of people with specific skills. Thus, the movement of labor among the 
INMR

20,1

companies in the cluster, together with geographical proximity, influences the transfer of knowledge.

This scenario converges with the fourth proposition of this study, translated into the following sentence: Proposition 4: The mobility of the workforce intensifies the transfer of knowledge between the organizations inserted in the cluster.

The evidence supporting the argument is:

At the beginning of the year we made a bank of consultants, among the professors who would like to do consultancy work inside the Park (...). We brought the companies together, identified who the teachers would be, and that resulted in some projects (Respondent 1).

So we have a very up-to-date view of the productive sector, it is experiencing it, it is bringing trends. Often he is also a teacher here and a teacher at other schools, so he sees what's going on, what are the trends (Respondent 2).

The most significant evidence in the aspect of the mobility of the workforce in the Technology Park of São José dos Campos refers to the performance of consultants between the different organizations, with predominance for the performance of the professors of the teaching and research institutions with the companies. There is a recognition on the part of the companies that the professors and researchers of the teaching and research institutions of the Park are specialists in areas of interest of the cluster and that the joint action between these organizations expands the companies' technological knowledge and innovation base (Bittencourt et al., 2019).

Regarding the movement of labor among companies, together with geographical proximity and the influence on knowledge transfer, this can be confirmed by the performance of professors from teaching and research institutions as consultants with companies, as well as the training of professionals in teaching institutions in the cluster, both because it is considered differentiated and due to the network of contacts established among the professionals.

The influence of the mobility of the workforce in the cluster can occur through the work of employees with previous experience of labor in other companies, suppliers with previous experience in other companies, consultants and training of professionals in the teaching institutions of the cluster, with more accentuated tendency for the last two factors, corroborating with proposition 4 where the mobility of the workforce intensifies the transfer of knowledge between the organizations inserted in the cluster.

\subsection{Analysis of proposition 5 - proximity intensifies the transfer of knowledge between organizations within the cluster}

Authors such as Vásquez-Urriago et al. (2016) and Bagley (2019) argue that geographical proximity facilitates the flow of knowledge between the organizations that are part of Technology Parks. It is important to highlight that, according to the authors, proximity should not be understood only geographically, but also from the technological and organizational points of view (structure, culture and language). This idea converges with the fifth and final proposition of this study: Proposition 5: Proximity intensifies the transfer of knowledge between organizations within the cluster.

The evidence supporting the argument is as follows:

I think it is this proximity to the companies (that favors it), it is this ease of need, you go and talk. I think for companies too, because it happens that the company says "I saw it in a lecture and decided to come here" (Respondent 7).

It is as if we belong to the same organization. They are different organizations, but they work together in the same environment (Respondent 2).

The central idea that has been repeated most is that the proximity between the organizations of the Technology Park of São José dos Campos, combined with cooperation, results in an 
environment conducive to the sharing of knowledge, innovation and technological development. This fact indicates that this dimension facilitates the flow of knowledge between the organizations that are part of Technology Parks, insofar as it has a positive effect on the interactions that occur, reduces the cost of searching for information and encourages long-term relationships that allow knowledge exchange most valuable.

It is observed that social interaction facilitates access and knowledge exchange between the Park's organizations, as occurs through informal conversations and visits to other organizations, in convergence with the idea that the creation and transfer of knowledge result in the interaction between tacit knowledge and explicit knowledge through social processes between the actors, not confined to the individual, and both dimensions of knowledge (tacit and explicit) interact in this process (Nonaka et al., 1996). This result shows that the proximity between the cluster organizations, the formal and informal connections between academia, industry and other institutions of different natures present in the cluster intensify the transfer of knowledge, as evidenced by Bagley (2019) and this study.

\section{Final considerations}

It is expected that organizations that operate in a network, more specifically in the form of clusters, having access to knowledge between organizations, will have the transfer of knowledge more intense among themselves than would be achieved if they acted in isolation. In the aspect of knowledge transfer between organizations, there are factors that can inhibit or facilitate this process and the understanding of these factors can lead to better management, improving and facilitating the flow of knowledge between participating organizations.

This work was based on the concepts of knowledge transfer, combined with the theoretical model of interorganizational networks and clusters. The results showed that the knowledge transfer in the cluster is influenced by several factors, such as: cooperation, relationship with institutions, workforce mobility and geographical proximity. Some act as facilitators, others act as inhibitors, preventing the emergence of knowledge transfer or restricting its results. Some factors can act both as facilitators (when their performance creates or expands the transfer of knowledge) and inhibitors (when their absence or greater performance inhibits the emergence or restricts the transfer of knowledge in the cluster).

\subsection{Contributions and implications}

This study represents an advance to the knowledge management literature in network environments. There is the presence of aspects indicating that knowledge goes beyond borders through dynamic and collaborative structures, reinforcing the premise that clusters must be perceived as an evolutionary system, the result of which is a greater capacity than they would achieve acting alone (Zaccarelli et al., 2008) and may have a highly similar pattern of activities (Todeva, Knoke, \& Keskinova, 2007) reinforcing the research of these authors. It also reinforces the studies of authors such as Castells \& Cardoso (2005), by highlighting that the network society is a social structure based on networks that generate, process and distribute information and the knowledge accumulated in the nodes of the network. This research complements the works of authors such as Tallman et al. (2004), Zeng (2008), Arvanitis et al. (2011), Hoffmann et al. (2014) and Vásquez-Urriago et al. (2016), Miranda and Borges (2019) regarding the transfer of knowledge in network environments, specifically in clusters in the technological segment.

The case of the São José dos Campos Technology Park network can serve as a basis for managers of other similar organizational arrangements, such as Industrial Districts and Business Incubators, as well as Technology Parks in other regions, with regard to increasing the capacity of regional innovation and development. The present work can also be used by managers and actors involved in the governance of these organizational arrangements, such as with regard to increasing the capacity for creation and the dissemination of knowledge 
INMR

20,1

among organizations, by stimulating the factors that facilitate this process and the restriction to the factors that inhibit it.

Another practical implication of the work is to emphasize the importance of collaboration in the knowledge transfer process, representing one of the major challenges for the development of companies and society. That being said, a greater impact is expected through the use of different mechanisms for collaboration and sharing of information and knowledge, encompassing academia, industry and government, the triple-helix actors and other stakeholders, which can serve as an example for creating environments and more collaborative ecosystems with potential for innovation.

\subsection{Limitation and future studies}

The first limitation refers to the fact that it is a cross-sectional study, that is, a research that reflects a certain moment in the network. As the networks are dynamic, studies that follow their development over time can enrich the discussion about the transfer of knowledge in corporate network environments and, in particular, in Technology Parks. The second limitation is the fact that the interviews were conducted for accessibility to respondents, whose data were obtained through nonparticipant observation and documentary analysis. Finally, as the research context was restricted to the activities of the São José dos Campos Technology Park network, although comparable, the results of the analyzes cannot be generalized to networks in other sectors or to other clusters.

It is suggested that future studies on the identification of factors that influence the transfer of knowledge in clusters be replicated in other organizational arrangements, such as business incubators and industrial districts, as well as in networks from other sectors and regions. It is understood that new research in different contexts will allow generalizations about the researched object, that is, the process of knowledge transfer in networks. Therefore, the following agenda for future studies is suggested: (1) a longitudinal study and monitoring of knowledge transfer in clusters and Technology Parks; (2) comparative studies between clusters and Technology Parks in other regions, on the knowledge creation and transfer process; (3) quantitative studies on the factors that influence the transfer of knowledge in a cluster, in order to increase the validity of the conceptual model of the collection instrument of the present study, seeking correlation between the factors and their result in performance.

\section{References}

Aguiar, H.de, Pereira, C., Donaire, D., \& Nascimento, P. (2017). Análise da competitividade de clusters de negócios de varejo: Ajuste de métricas através de uma aplicação no cluster varejista de moda do bom retiro. REGE Revista de Gestão, 24(2), 122-133.

Argote, L., \& Ingram, P. (2000). Knowledge transfer: A basis for competitive advantage in firms. Organizational Behavior and Human Decision Processes, 82(1), 150-169.

Arvanitis, S., Kubli, U., \& Woerter, M. (2011). Knowledge and technology transfer activities between firms and universities in Switzerland: An analysis based on firm data. Industry and Innovation, 18(4), 369-392.

Asheim, B. T., \& Isaksen, A. (2002). Regional innovation systems: The integration of local 'sticky' and global 'ubiquitous' knowledge. The Journal of Technology Transfer, 27(1), 77-86.

Bagley, M.J. (2019). Networks, geography and the survival of the firm. Journal of Evolutionary Economics, 29(4), 1173-1209.

Barratt, M., Choi, T.Y., \& Li, M. (2011). Qualitative case studies in operations management: Trends, research outcomes, and future research implications. Journal of Operations Management, 29(4), 329-342.

Bittencourt, B., Zen, A., \& Prévot, F. (2019). Innovation Capability of Clusters: Understanding the innovation of geographic business networks. RBGN-Revista Brasileira de Gestão de Negócios, 21(S.1.), 647-663. 
Cassanego Júnior, P.V., Boaventura, J.M.G., Azevedo, A.C., \& Telles, R. (2019). Governance in business clusters: Proposal for an application of an analytical model. Entrepreneurship \& Regional Development, 31(9-10), 984-1010.

Castells, M., \& Cardoso, G. (2005). The Network Society. From Knowledge to Policy. Washington: John Hopkins.

Castro, I., Nagano, M., \& Ribeiro, S. (2019). Elements that influence knowledge sharing in the university-industry-government collaboration Case studies in Brazil. REGE Revista de Gestão, 26(1), 61-72.

Cohen, W.M., \& Levinthal, D.A. (1990). Absorptive capacity: A new perspective on learning and innovation. Administrative Science Quarterly, 35(1), 128-152.

Corbin, J., \& Strauss, A. (1996). Analytic ordering for theoretical purposes. Qualitative Inquiry, 2(2), $139-150$.

Correia, I. (2007). Spillovers de Conhecimento e Desenvolvimento Regional: Evidência de Portugal. Revista portuguesa de estudos regionais, 13, 67-80.

Costa Neto, E., Perin, M., \& Ferreira, G. (2019). Transferência de conhecimento: A perspectiva empresarial. Revista Gestão \& Tecnologia, 19(2), 195-216.

Eisenhardt, K.M. (1989). Building theories from case study research. Academy of Management Review, 14(4), 532-550.

Etzkowitz, H. (2003). Innovation in innovation: The triple helix of university-industry-government relations. Social Science Information, 42(3), 293-337.

Fioravanti, V.S.L., \& Macau, F.R. (2017). Um modelo conceitual para o processo de transferência do conhecimento em cluster. Navus: Revista de Gestão e Tecnologia, 7(1), 111-134.

Hoffmann, E., Lopes, G., \& Medeiros, J. (2014), Knowledge transfer among the small businesses of a Brazilian cluster. Journal of Business Research, 7(5), 856-864.

Humphrey, J., Todeva, E., Armando, E., \& Giglio, E. (2019). Global value chains, business networks, strategy and international business: The convergence. RBGN - Revista Brasileira de Gestão de Negócios, 21(S.1.), 607-627.

Jarvenpaa, S.L., \& Wernick, A. (2011). Paradoxical tensions in open innovation networks. European Journal of Innovation Management, 14(4), 521-548.

Jiang, J., Goel, R.K., \& Zhang, X. (2019). Knowledge flows from business method software patents: Influence of firms' global social networks. The Journal of Technology Transfer, 44(4), 1070-1096.

López-Rubio, P., Roig-Tierno, N., \& Mas-Verdú, F. (2021). Assessing the origins, evolution and prospects of national innovation systems. Journal of the Knowledge Economy, 1-24.

Lundvall, B.Å., Johnson, B., Andersen, E.S., \& Dalum, B. (2002). National systems of production, innovation and competence building. Research Policy, 31(2), 213-231.

Malmberg, A., \& Power, D. (2005). How do firms in clusters create knowledge? Uppsala University, 12, 409-431.

Martins, C., Fiates, G., Dutra, A., \& Venâncio, D. (2015). Redes de Interação a partir de Incubadoras de Base Tecnológica: A Colaboração Gerando Inovação. Revista Gestão \& Tecnologia, 14(2), $127-150$.

Minello, I.F., Marinho, E.S., \& Bürger, R.E. (2017). Processo de Incubação como Estimulador de Inovação: Um Estudo com Empresas Incubadas de Base Tecnológica. Revista Eletrônica de Estratégia \& Negócios, 10(3), 3-26.

Miranda, M.G., \& Borges, R. (2019). Technology-based business incubators: An Exploratory analysis of Intra-organizational social networks. Innovation \& Management Review, 16(1), 36-54.

Molina-Morales, F.X. (2001). Human capital in the industrial districts. Human Systems Management, 20, 319-331.

Technological innovation clusters 
INMR

20,1

Morosini, P. (2004). Industrial clusters, knowledge integration and performance. World Development, 32, 305-326.

Nonaka, L., Takeuchi, H., \& Umemoto, K. (1996). A theory of organizational knowledge creation. International Journal of Technology Management, 11(7-8), 833-845.

Paulin, D., \& Winroth, M. (2013). Facilitators, inhibitors, and obstacles-A refined Categorization regarding barriers for knowledge transfer, sharing, and flow. In Proceedings of the 10th International Conference on Intellectual Capital, Knowledge Management and Organisational Learning, 320, ICICKM.

Pereira, C.G., Silva, R.R., Lavoie, J.R., \& Porto, G.S. (2018). Technological cooperation network in biotechnology: Analysis of patents with Brazil as the priority Country. Innovation and Management Review, 15(4), 416-434.

Pique, J.M., Berbegal-Mirabent, J., \& Etzkowitz, H. (2018). Triple helix and the evolution of ecosystems of innovation: The case of silicon valley. Triple Helix, 5(1), 1-21.

Porter, M.E. (1990). The Competitive Advantage of Nations. New York, NY: Free Press.

Powell, W. (1998). Learning from collaboration: Knowledge and networks in the biotechnology and pharmaceutical industries. California Management Review, 40, 228-240.

Ribeiro, S., \& Nagano, M. (2018). Main dimensions that impact knowledge management and university-business-government collaboration in the Brazilian scenario. REGE Revista de Gestão, 25(3), 258-273.

Roldan, L.B., Hansen, P.B., \& Garcia-Perez-de-Lema, D. (2018). The relationship between favorable conditions for innovation in technology Parks, the innovation produced, and companies' performance: A framework for an analysis model. Innovation and Management Review, 15(3), 286-302.

Santos, J.B. (2020). Knowledge-intensive business services and innovation performance in Brazil. Innovation and Management Review, 17(1), 58-74.

Sarach, L. (2015). Analysis of cooperative relationship in industrial cluster. Procedia - Social and Behavioral Sciences, 191, 250-254.

Silva, S.S., Feldmann, P.R., Spers, R.G., \& Bambini, M.D. (2019). Analysis of the process of technology transfer in public research institutions: The Embrapa agrobiology case. Innovation and Management Review, 16(4), 375-390.

Siqueira, J., Rocca, M., \& Telles, R. (2015). Atributos e Imagem dos Clusters de Negócios Varejistas. Revista Gestão \& Tecnologia, 15(2), 29-49.

Stocker, F., Mascena, K.M.C., Azevedo, A.C., \& Boaventura, J.M.G. (2019). Teoria de Redes de Influências de 'stakeholders': uma abordagem revisitada. Cadernos EBAPE.BR, 17(spe), 673-688.

Szulanski, G. (2000). The process of knowledge transfer: A diachronic analysis of stickiness. Organizational Behavior and Human Decision Processes, 82(1), 9-27.

Tallman, S., Jenkins, M., Henry, N., \& Pinch, S. (2004). Knowledge, clusters, and competitive advantage. Academy of Management Review, 29(2), 258-271.

Todeva, E., Knoke, D., \& Keskinova, D. (2007). Porous and Fuzzy Boundaries. Minneapolis: Minnesota University.

Vásquez-Urriago, A.R., Barge-Gil, A., \& Rico, M. (2016). Science and technology Parks and cooperation for innovation: Empirical evidence from Spain. Research Policy, 45, 137-147.

Williams, D.R., \& Pouder, R.W. (2019). Are explicit knowledge transfers clustered or diffused in the US biopharmaceutical market sector?. Entrepreneurship \& Regional Development, 1-16.

Yin, R.K. (2010). Estudo de caso: planejamento e métodos, 4. Ed, Porto Alegre: Bookman.

Zaccarelli, S.B., Telles, R., Siqueira, J.P.L., Boaventura, J.M.G., \& Donaire, D. (2008). Clusters e Redes de Negócios: uma nova visão para a gestão dos negócios. Atlas: São Paulo. 
Zaheer, A., Gözübüyük, R., \& Milanov, H. (2017). It's the connections: The network perspective in interorganizational research. Academy of Management Perspectives, 24(1), 10-5465.

Zeng, D.Z. (2008). Knowledge, Technology, and Cluster-based growth in Africa. Washington: The World Bank.
Technological innovation clusters

Zucker, L.G., Darby, M.R., \& Armstrong, J. (1998). Geographically localized knowledge: Spillovers or markets? Economic Inquiry, 26, 65-86.

\section{Corresponding author}

Vania Lopes Simoes Fioravanti can be contacted at: vania.simoes@unifesp.br

For instructions on how to order reprints of this article, please visit our website:

www.emeraldgrouppublishing.com/licensing/reprints.htm

Or contact us for further details: permissions@emeraldinsight.com 